\title{
Removal of methylene blue dye from aqueous solution by nonliving lichen (Pseudevernia furfuracea (L.) Zopf.), as a novel biosorbent
}

\author{
Hülya Koyuncu' ${ }^{1}$ Ali Rıza Kul ${ }^{2}$
}

Received: 8 October 2019 / Accepted: 3 February 2020 / Published online: 10 February 2020

(c) The Author(s) 2020

\begin{abstract}
The use of lichens is insufficient in industry. To the best of our knowledge, there is no study on the use of lichens in the removal of dyes from aqueous media. The aim of this study is to draw attention to the biosorption capabilities of lichens which are natural, renewable and inexpensive sources, and to investigate the usability of nonliving lichen Pseudevernia furfuracea (L.) Zopf. (LPF) in methylene blue (MB) dye removal from aqueous solution. With the green chemistry approach, no chemical treatment was applied to the LPF and it was used as a natural biosorbent for the biosorption. The LPF samples were prepared and characterized and performed batch mode biosorption experiments studying the effect of various parameters on MB biosorption. The experimental data were fitted with four different kinetic models (pseudo-first order, pseudo-second order, Elovich model and intra-particle diffusion) which were evaluated for their validity. Identification of the biosorption mechanism of MB onto the LPF was performed by isotherm studies via three isotherm models [Langmuir, Freundlich and Dubinin-Radushkevich (D-R)], and the parameters of each model were determined. It was concluded that the biosorption rate and yield were high, the type of biosorption of MB onto the LPF was defined as chemical biosorption, and the surface of the LPF was decided energetically heterogeneous. The results indicate that the LPF biomass can be attractive options for MB dye removal from aqueous media.
\end{abstract}

Keywords Biosorption $\cdot$ Equilibrium $\cdot$ Kinetics $\cdot$ Lichen (Pseudevernia furfuracea) $\cdot$ Methylene blue

\section{Introduction}

MB dye has wide range applications as a colouring agent for textile, paint, paper and food (Salimi and Roosta 2019; Gupta et al. 2012; Zhang et al. 2013). However, MB has highly toxic and carcinogenic properties in living organisms. Therefore, the removal of MB from wastewaters is very important (Altenor et al. 2009; Nezamzadeh-Ejhieh and Karimi-Shamsabadi 2014). Many techniques which are adsorption, chemical coagulation, degradation, solvent extraction, oxidation, membrane filtration are applicable for

Hülya Koyuncu

hulya.koyuncu@btu.edu.tr; hulyakoyuncu06@yahoo.com.tr

Ali Rıza Kul

alirizakul@yyu.edu.tr

1 Chemical Engineering Department, Faculty of Engineering and Natural Sciences, Bursa Technical University, 16310 Bursa, Turkey

2 Chemistry Department, Faculty of Art and Science, Yuzuncu Yil University, 65080 Van, Turkey removal of MB dye from wastewater (Bazrafshan et al. 2015; Goyal et al. 2018; Hua et al. 2017; Ledakowicz et al. 2017; Ma et al. 2018). Among all these techniques, adsorption is a commonly used dependable method. Adsorption method has some advantages such as low operating costs and flexibility. But the high price of the adsorbents is the main disadvantage of this method (Koyuncu and Kul 2019). Many researchers have investigated to utilize cheap adsorbents to remove MB dye from wastewater. Some biological materials such as agricultural waste, some plants, fruit peels, even fungi and algae were used as cheap and effective adsorbents and called as biosorbents (Subramaniam and Ponnusamy 2015; Adegoke and Bello 2015; Sivalingam et al. 2019; Danish et al. 2018). Moghazy et al. (2019) investigated that micro-grinded dried biomass of two macro-algal species as complementary biosorbent materials for MB removal from wastewater. The optimum $\mathrm{pH}$ value was selected as 7 for the biosorption. The kinetic data were well described by the PSO better than PFO kinetic model. Lebron et al. (2018) studied the equilibrium, kinetics and thermodynamic viability of MB biosorption by Chlorella pyrenoidosa (C. pyrenoidosa) and Spirulina 
maxima (S. maxima). They reported that the biosorption of MB best described by Freundlich and Temkin isotherm models, and the PSO kinetic model was the best fit for $C$. pyrenoidosa and S. maxima. Ferrero (2007) investigated the adsorption of MB on wood sawdust from walnut, cherry, oak and found that the adsorption kinetics best fit to PSO model and the adsorption capacities were 45, 38, 29 and $28 \mathrm{mg} \mathrm{g}^{-1}$, respectively. Hamdaoui (2006) studied the adsorption of MB on sawdust from natural cedar and reported that the maximum uptake of MB was at $\mathrm{pH}$ 7, and the PSO model best described adsorption kinetic data. There is no study in the literature about the use of lichens for the removal of dyes from aqueous media.

However, among all the biosorbents lichens are very promising biosorbent which has high surface area. Also, they have large cellular medullary cavities which can accumulate certain pollutants. Lichens are composite organisms consisting of fungi and algae or cyanobacteria in symbiotic association. Lichens can be found almost anywhere in the world since they can withstand even the toughest ecological conditions. They are found in leafy, branched and crusty forms on trees, soil and rocks. There are 20,000 known species of lichen worldwide (Hale 1974; Aslan et al. 2006; Sarikurkcu et al. 2016). Lichens have been used for various purposes such as paint, pharmaceutical, perfume, food and chemical industries from ancient times to today. Also, because of their sensitivity to the environmental pollution, they are used as bioindicators or biomonitors for monitoring and controlling air and environmental pollution. Many studies have been published on regarding the use of lichens as biomonitor of atmospheric change and organic air pollutants (Van derWat and Forbes 2015; Paoli et al. 2011; Paolia et al. 2015; Malaspinaa et al. 2018). But, there are few studies in the literature about the utilization of the lichens as biosorbent for only the removal of heavy metal ions from aqueous solution (Kılıc et al. 2014; Gül et al. 2019). In this study, the LPF, which is a common lichen species in the conifer-hardwood forests of Turkey, was chosen as a natural and easily obtainable biosorbent for the removal of MB from aqueous solution. The effect of several parameters on the biosorption and the suitability of various kinetic and isotherm models was studied in detail.

\section{Materials and methods}

\section{Preparation and characterization of biosorbent}

The LPF samples were collected from the forest near Yapraklı Büyük Yayla Forest Çankırı, Turkey. The samples were cleaned from various materials using microscope (Leica DM2500 M), and then, they were washed with double-distilled water to remove extraneous materials and salts.
They were then dried and inactivated in an oven (Memmert) at $378 \mathrm{~K}$ for $24 \mathrm{~h}$ until no variation in the sample weight observed. The inactivated dried biomass was ground freezing with liquid nitrogen, sieved (Retsch AS300 Control), and the particles with an average of $63 \mu \mathrm{m}$ were used for biosorption experiments.

$\mathrm{KBr}$ discs (Specac hydraulic press) were prepared from sieved the LPF. Fourier transform infrared spectrum of the discs was recorded at $400-4000 \mathrm{~cm}^{-1}$ wavenumber range. Nicolet-IS50 model FT-IR spectrophotometer was used.

Specific surface area (BET) and pore size distribution of the LPF were determined using a Micrometrics-Tristar II series volumetric gas adsorption instrument. The determination was based on measurement of the corresponding nitrogen adsorption isotherm at $77 \mathrm{~K}$ (Koyuncu et al. 2007). Before measurement was started, degas procedure was carried out under reduced pressure at $373 \mathrm{~K}$ for $1 \mathrm{~h}$ and $423 \mathrm{~K}$ for $5 \mathrm{~h}$ (Kul and Koyuncu 2010).

Surface morphology of the LPF before and after biosorption of MB was obtained by SEM (Zeiss GeminiSEM 300) at an operating voltage $5 \mathrm{kV}$. The samples were coated gold and palladium for effective imaging.

\section{Preparation of stock solutions}

MB (1.15943.0025) was purchased from Merckmillipore Co. The stock solution of MB was prepared by dissolving a weighed quantity of $\mathrm{MB}$ in double-distilled water. The required concentrations $(10,20,30,40,50,60$ and $70 \mathrm{mg} \mathrm{L}^{-1}$ ) were prepared from the stock solution by dilution with double-distilled water (Elga Option-Q) at room temperature (Kul and Koyuncu 2010). For pH adjustment, analytical reagent grade $\mathrm{HCl}$ (Merckmillipore 1.00317.2500) and $\mathrm{NaOH}$ (Merckmillipore 1.06462.1000) were used.

\section{Biosorption studies}

Biosorption studies were performed by the batch technique at different temperatures $(298 \mathrm{~K}, 308 \mathrm{~K}$ and $318 \mathrm{~K})$. The batch mode biosorption was selected due to its availability, facility of operation and reliability. Different methods can be used such as oxidation, flocculation and membrane separation for the removal of MB from aqueous solution. But, these methods have some disadvantages. For instance, in the oxidation and flocculation methods a lot of mud is produced, and the membrane separation needs high pressures. There are many studies in the literature about the biosorption of MB from aqueous solution by different biosorbents. However, there is no study on the biosorption of MB from aqueous solution by using the LPF or other lichens. 
Initial concentrations of $\mathrm{MB}$ dye were 10, 20, 30, 40, 50,60 and $70 \mathrm{mg} \mathrm{L}^{-1}$, and $2 \mathrm{~g} \mathrm{~L}^{-1}$ of the LPF biomass was added in each MB solution. A temperature-controlled water bath shaker (Thermal H11960) was used for all the experiments. The biosorption data from aqueous solutions were obtained using the immersion method. The solutions were shaken at $200 \mathrm{rpm}$ for $140 \mathrm{~min}$, and the samples were taken at certain time intervals $(5,10,15,20,25,30$, $35,40,50,60,70,80,90,100,110,120,140 \mathrm{~min})$. Since the highest biosorption efficiency was taken at $\mathrm{pH} 8.5$ in the preliminary studies, all experiments were performed at this $\mathrm{pH}$ value. The $\mathrm{pH}$ of each solution was adjusted at 8.5 by using $0.1 \mathrm{~N} \mathrm{HCl}$ and $0.1 \mathrm{~N} \mathrm{NaOH}$ solution. Tetra $\mathrm{PH}-2005 \mathrm{pH}$ metre was used for $\mathrm{pH}$ measurement.

Then, the samples were centrifuged (NF 800R) to remove suspended the LPF biomass at $5000 \mathrm{rpm}$ for $10 \mathrm{~min}$, and then, the supernatants were analysed for residual MB concentration by UV/VIS spectrophotometer (Shimadzu UVmini-1240 Spectrophotometer) at $660 \mathrm{~nm}$ wavelength (Koyuncu 2008).

The biosorption capacity of the LPF was calculated as follows;

$q_{\mathrm{e}}=\left[\left(C_{o}-C_{\mathrm{e}}\right) V\right] / \mathrm{m}$

where $q_{\mathrm{e}}$ is the biosorption capacity of MB on the biosorbent $\left(\mathrm{mg} \mathrm{g}^{-1}\right), C_{0}$ is the initial MB concentration $\left(\mathrm{mg} \mathrm{L}^{-1}\right), C_{\mathrm{e}}$ is the equilibrium $\mathrm{MB}$ concentration $\left(\mathrm{mg} \mathrm{L}^{-1}\right), \mathrm{m}$ is the mass of the LPF used (g) and $V$ is the volume of MB solution (L).

\section{Results and discussion}

\section{Characterization of the biosorbent}

The FT-IR analysis was carried out to determine the functional groups present in the LPF in the wavenumber range of $400-4000 \mathrm{~cm}^{-1}$. The FT-IR spectrum of the LPF biomass is shown in Fig. 1. The broadband at $3379 \mathrm{~cm}^{-1}$ was due to stretching vibrations of structural $-\mathrm{OH}$ groups. The peak at $2917 \mathrm{~cm}^{-1}$ was aliphatic stretching of $\mathrm{C}-\mathrm{H}$ groups. The absorption band at $1610 \mathrm{~cm}^{-1}$ was related to stretching vibrations of aromatic $-\mathrm{C}=\mathrm{O}$ and $-\mathrm{C}=\mathrm{C}$ bonds in carboxylic acid anions. The peaks at $1155 \mathrm{~cm}^{-1}, 1204 \mathrm{~cm}^{-1}$ and $1242 \mathrm{~cm}^{-1}$ were from stretching vibrations of the ester groups. The peak at $1294 \mathrm{~cm}^{-1}$ was attributed to symmetrical vibration of $-\mathrm{COO}$ bond. The peak observed at $1018 \mathrm{~cm}^{-1}$ was assigned to stretching vibration of $\mathrm{C}-\mathrm{O}$ bonds.

Nitrogen adsorption isotherms of the LPF are shown in Fig. 2. The isotherm curve was a typical type II adsorption isotherm according to the IUPAC classification standard (Fig. 2). The specific surface area of the LPF biomass was calculated by applying BET method. The BET specific surface area was found as $0.76 \mathrm{~m}^{2} \mathrm{~g}^{-1}$. Komaty et al. (2016) have reported that the BET specific surface area of milled (mortar) Pseudevernia furfuracea was $1.8 \mathrm{~m}^{2} \mathrm{~g}^{-1}$. Pore size and its distributions are given in Fig. 3. The pore size distribution was found in the mesopore region (Kul and Koyuncu 2010). The sample exhibited maxima in differential pore volume at about $146.9 \AA$ (14.69 nm) in pore diameter (Fig. 3).

SEM images of the LPF indicated that the LPF has porous and heterogeneous surface (Fig. 4a). The high uptake of MB

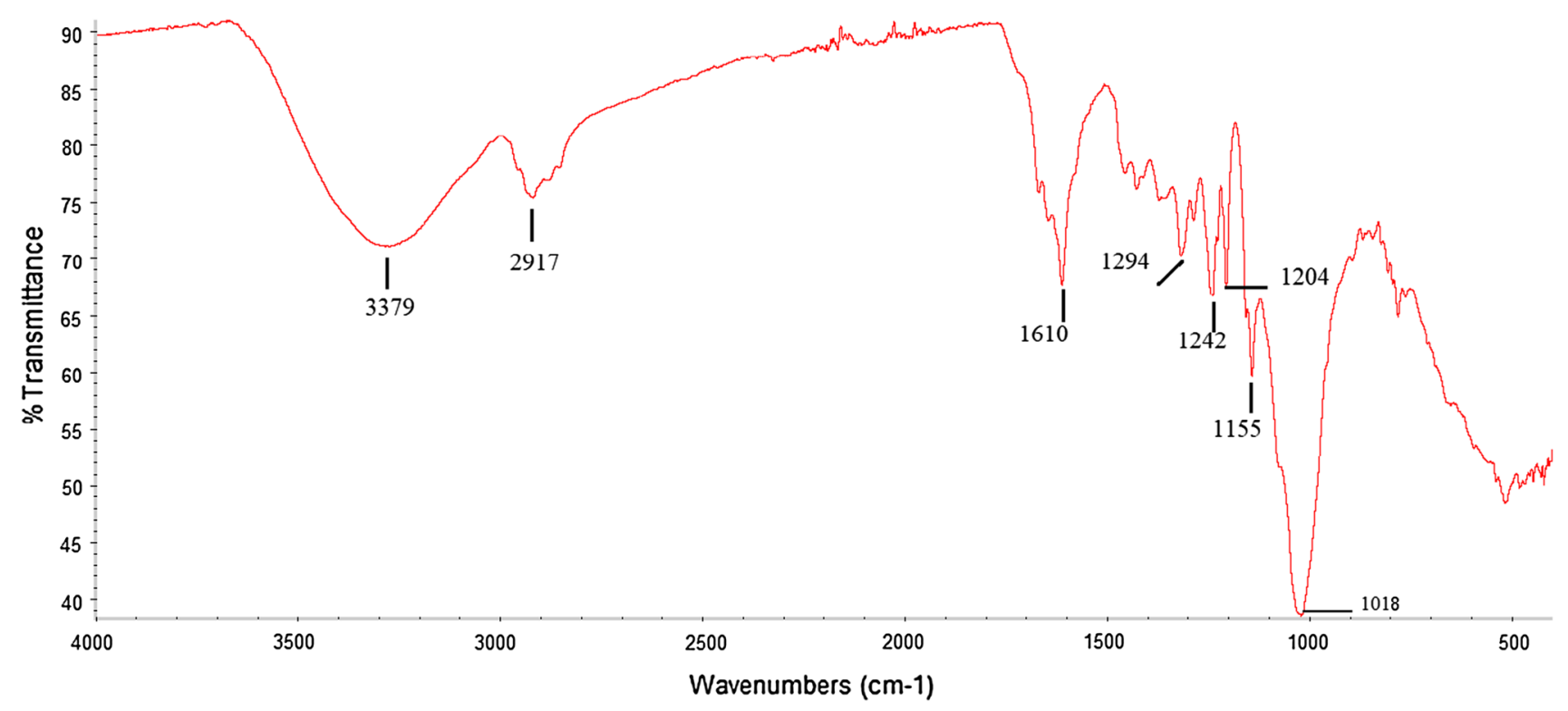

Fig. 1 FT-IR spectrum of the LPF 
Fig. 2 Nitrogen adsorption isotherm of the LPF

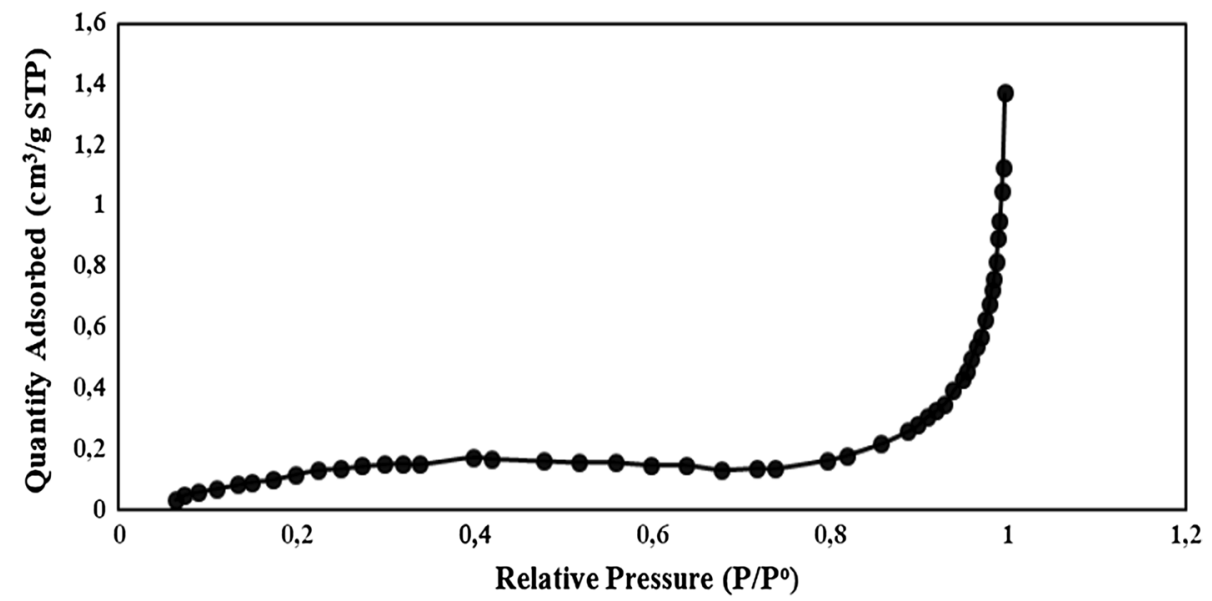

Fig. 3 Pore size distribution of the LPF

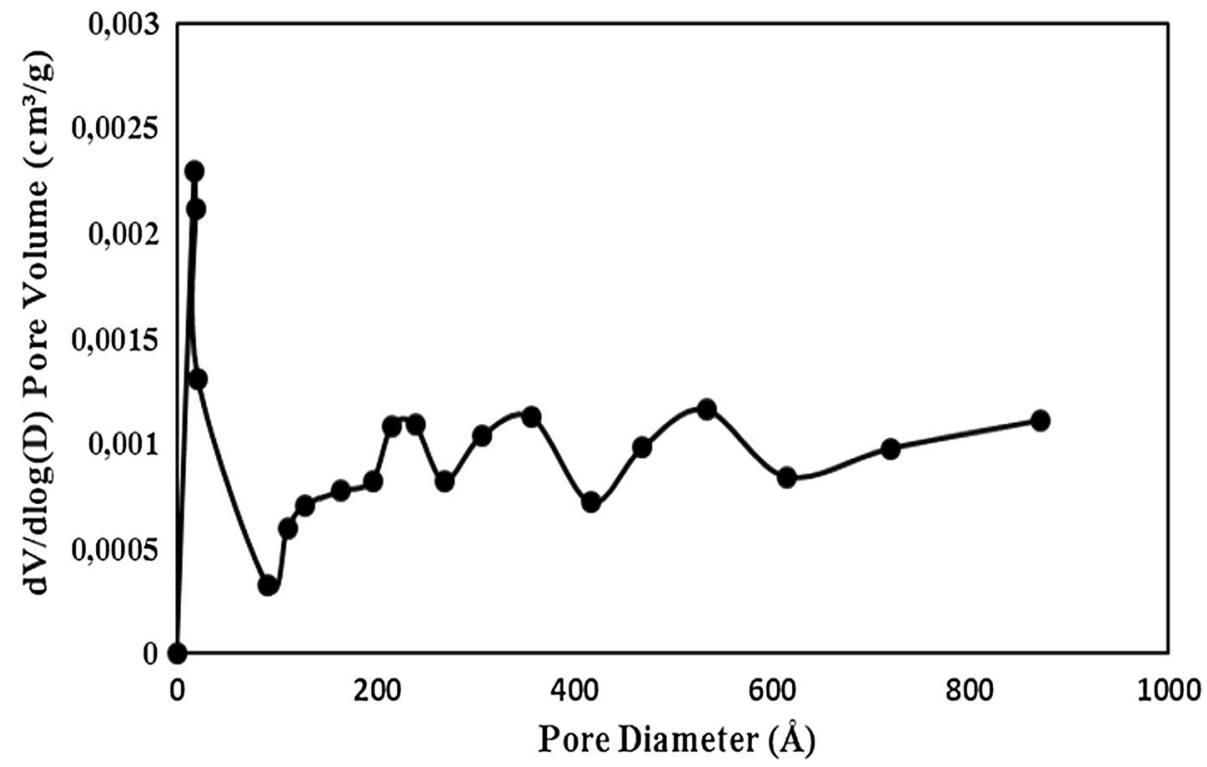

might be attributed of these surface properties. It is seen that from Fig. 4b, MB molecules occupied all the pores and surface of the LPF. Also, EDX results (Fig. 4c, d) showed that the biosorption of $\mathrm{MB}\left(\mathrm{C}_{16} \mathrm{H}_{18} \mathrm{ClN}_{3} \mathrm{~S}\right)$ changed the elemental composition (in per cent) of the surface.

\section{The effect of various parameters on MB biosorption}

The solution $\mathrm{pH}$ was very important parameter for the biosorption studies. Preliminary studies were carried out at different $\mathrm{pHs}(3,5,8,10$ and 12) to determine the optimum $\mathrm{pH}$, and the biosorption efficiencies were calculated. The highest biosorption efficiency of $\mathrm{MB}$ was determined at $\mathrm{pH}$ 8.5 (Fig. 5). At low pHs (acidic), positive charge distribution occurs due to protonation on the LPF surface, and negative charge distribution occurs at high pHs (alkaline) due to deprotonation on the LPF surface. Therefore, at acidic $\mathrm{pHs}$, the positively charged the LPF surface repelled positively charged MB (cationic dye) molecules, while at alkaline pHs, the negatively charged LPF surface rapidly attracted positively charged MB molecules.

The effect of contact time on the biosorption of $\mathrm{MB}$ onto the LPF at various initial concentrations and temperatures is shown in Fig. 6a-c. As shown Fig. 6a-c, the dynamic equilibrium was established in 90 min. However, the biosorption continued until 120 min with a very small removal of $\mathrm{MB}$. The biosorption of $\mathrm{MB}$ contains three steps with the increase in contact time. Step-1; the biosorption process in the first $40 \mathrm{~min}$, the surface of the LPF has many empty active sites for MB molecules, and biosorption rate is very fast; step-2; the biosorption at the contact time from 40 to $70 \mathrm{~min}$, since the active sites on the surface of the LPF are partially occupied by MB molecules, the active sites on the surface are reduced, and 
(a)

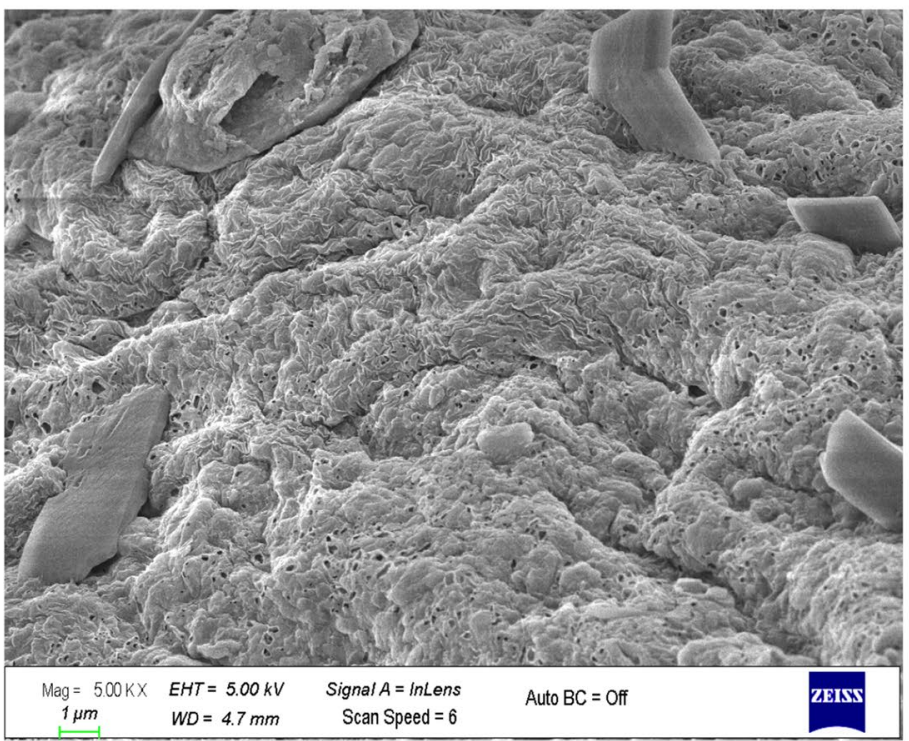

(b)

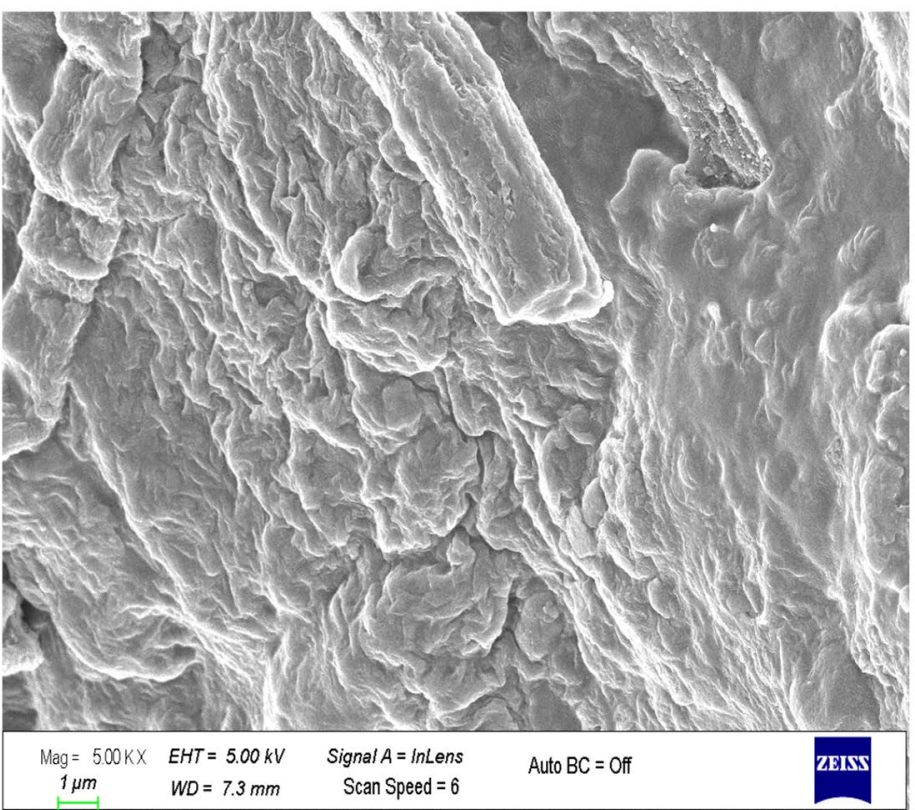

(c)

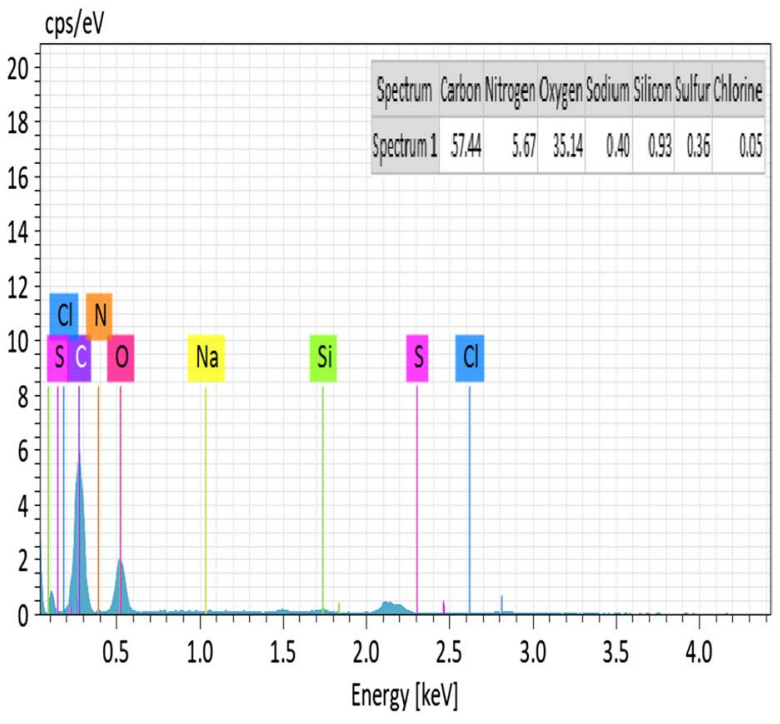

(d)

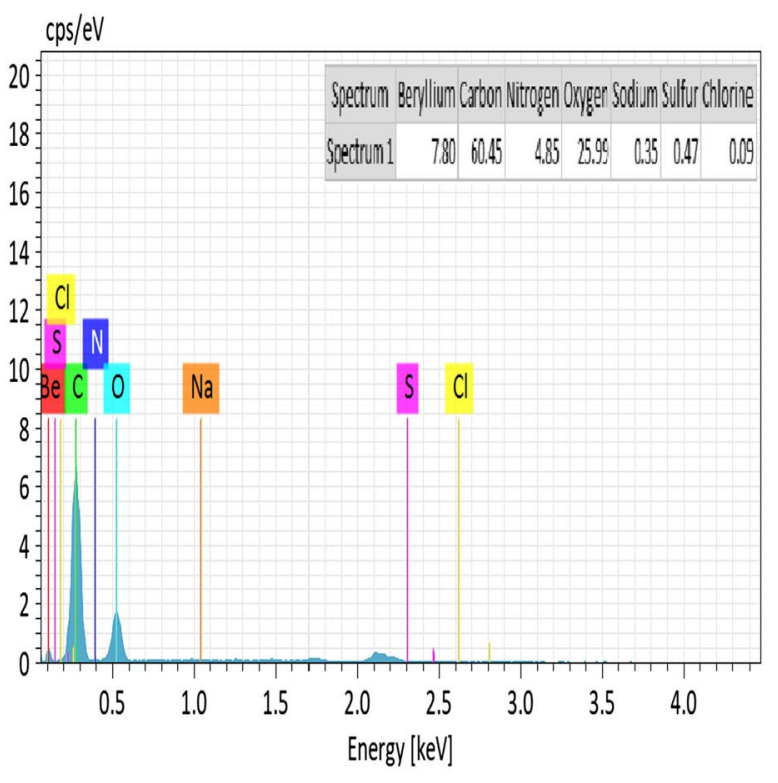

Fig. 4 SEM images of LPF (a before and $\mathbf{b}$ after biosorption of MB) and EDX results (c before and $\mathbf{d}$ after biosorption of MB)

biosorption rate is reduced; step-3; the biosorption process approaching equilibrium after $80 \mathrm{~min}$, very limited space site available for $\mathrm{MB}$ molecules, and biosorption rate is very slow. It can be stated that the biosorption capacity $\left(q_{\mathrm{t}}\right)$ of MB increases with increasing initial MB concentration. In addition, biosorption capacity $\left(q_{\mathrm{t}}\right)$ of $\mathrm{MB}$ rises with increasing temperature (Fig. 6a-c). Similar results have been reported by Zeng et al. (2015), Danish et al. (2018), Wang et al. (2018) and Khalili et al. (2018).
The temperature has a great effect on the biosorption since rising the temperature increases the mobility of $\mathrm{MB}$ molecules and decreases the solution viscosity (Kul and Koyuncu 2010). Thus, MB ions can access to small pores of the LPF. In addition, the increase in temperature can enlarge small pores. The biosorption efficiency of MB was calculated by the equation expressed as follows; 
Fig. 5 The effect of $\mathrm{pH}$ on the biosorption $(298 \mathrm{~K}, 70 \mathrm{ppm}$ initial concentration of $\mathrm{MB}$ )
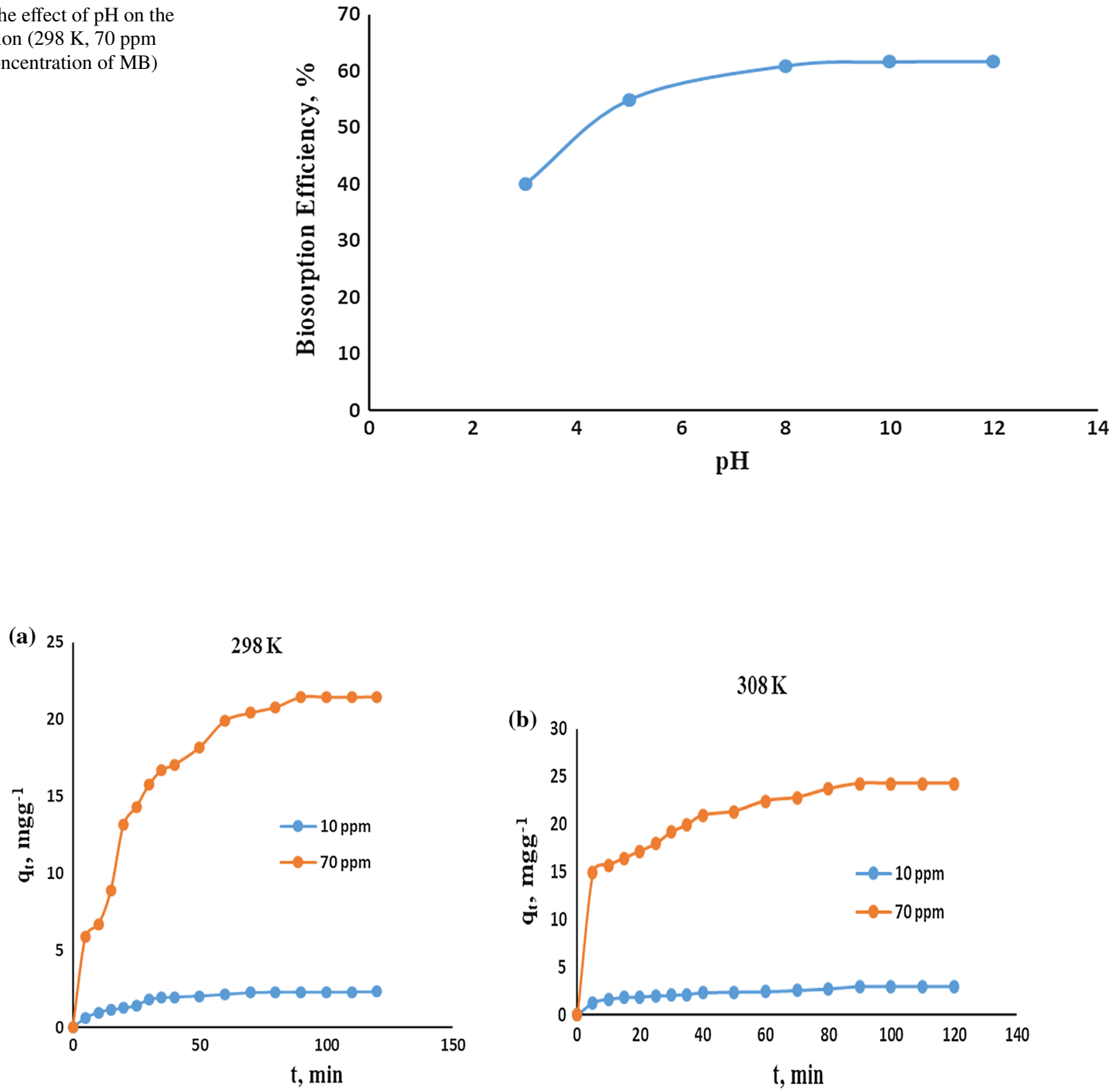

$318 \mathrm{~K}$

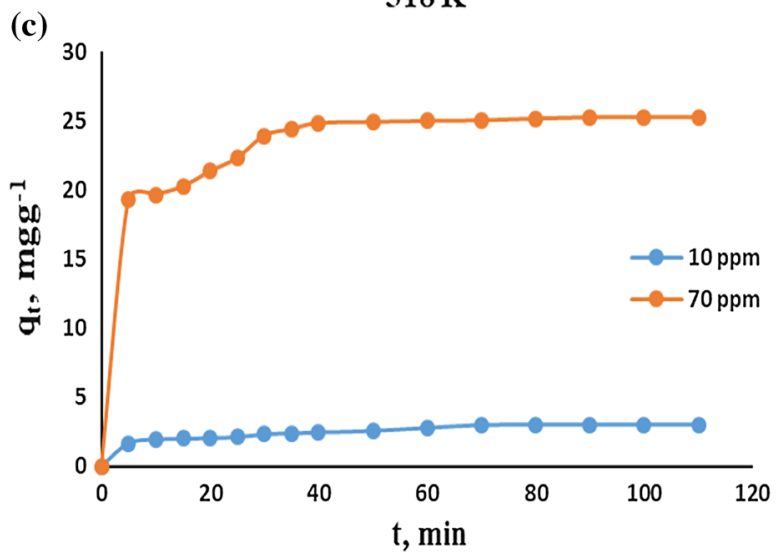

Fig. 6 The effect of contact time on the biosorption at various initial concentrations and temperatures (a 298 K, b 308 K, c 318 K) 
Biosorption efficiency $(\%)=\left[\left(C_{0}-C_{\mathrm{e}}\right) / C_{0}\right] \cdot 100$

The biosorption efficiency become greater with increasing temperature and initial concentration of $\mathrm{MB}$. When the temperature was increased from 298 to $318 \mathrm{~K}$, the biosorption efficiency increased slightly from 61.20 to $72.18 \%$ (Table 1). The results of the published studies on the removal of MB with different adsorbents at different temperatures are consistent with our results (Danish et al. 2018; Wang et al. 2018; and Khalili et al. 2018).

\section{Biosorption kinetics}

For explanation of biosorption kinetics and mechanism, experimental data were fitted to kinetic models. Four different kinetic models (PFO, PSO, EM and IDM) were used in this study.

PFO kinetic model According to this model, the number of unoccupied biosorptive sites decides the biosorption rate. The linear form of PFO model equation given by Lagergren (1898) is,

$\ln \left(q_{\mathrm{e}}-q_{\mathrm{t}}\right)=\ln q_{\mathrm{e}}-k_{1} t$

where $k_{1}\left(\mathrm{~min}^{-1}\right)$ is the rate constant biosorption, and $q_{\mathrm{e}}$ and $q_{\mathrm{t}}$ are the amounts of $\mathrm{MB}$ biosorbed $\left(\mathrm{mg} \mathrm{g}^{-1}\right)$ at equilibrium and at time $t(\mathrm{~min})$, respectively. Values of $k_{1}$ at 298-318 K were calculated from the plots of $\ln \left(q_{\mathrm{e}}-q_{\mathrm{t}}\right)$ versus $t$ (Fig. 7a). The $R^{2}$ values obtained were lower than that of the PSO, EM and IDM kinetic models. Also, there is no closeness between calculated $q_{\mathrm{e}}$ values obtained from the linear plot and experimental $q_{\mathrm{e}}$ values (Table 2 ). In addition, root mean square errors (RMSE), the sum of square errors (SSE), Chi-squares $\left(\chi^{2}\right)$ and Akaike information criterion (AIC, AICc) tests were higher than that of the PSO, EM and IDM kinetic models (Table 3). This indicates that the biosorption of MB does not follow PFO kinetics. Several authors have reported that adsorption of MB on different adsorbents does not fit the PFO kinetic model (Sivalingam et al. 2019; Siddiqui et al. 2018).

PSO kinetic model According to this model, the adsorption rate depends both the properties of the adsorbent and

Table 1 Biosorption efficiencies at the studied lowest and highest initial concentrations of $\mathrm{MB}$ at various temperatures

\begin{tabular}{llll}
\hline $\begin{array}{l}\text { Initial concentration, } \\
\mathrm{mg} \mathrm{L}^{-1}\end{array}$ & \multicolumn{3}{l}{ Biosorption efficiency (\%) } \\
\cline { 2 - 4 } & $298 \mathrm{~K}$ & $308 \mathrm{~K}$ & $318 \mathrm{~K}$ \\
\hline 10 & 46.30 & 59.90 & 60.30 \\
70 & 61.24 & 69.27 & 72.18 \\
\hline
\end{tabular}

the properties of the solute molecules. Linear form of PSO kinetic model was expressed as follows;

$t / q_{\mathrm{t}}=1 / k_{2} q_{\mathrm{e}}^{2}+t / q_{\mathrm{e}}$

where $q_{\mathrm{e}}$ and $q_{\mathrm{t}}$ are the amounts of MB biosorbed at equilibrium and any time $\left(\mathrm{mg} \mathrm{g}^{-1}\right)$, respectively. $k_{2}$ is the rate constant for PSO model $\left(\mathrm{g} \mathrm{mg}^{-1} \mathrm{~min}^{-1}\right)$. The PSO kinetic model constants were determined from the plots of $t / q_{t}$ versus $t$.

The initial biosorption rate was given as follows;

$k_{0}=k_{2} q_{\mathrm{e}}^{2}$

The values of correlation factor $R^{2}$, obtained from the plots of PSO kinetic model (Fig. 7b), are greater $\left(R^{2}>0.99\right)$ than that of the PFO, EM and IDM kinetic models (Table 2). It also showed a good conformity between the experimental and the calculated $\mathrm{q}_{\mathrm{e}}$ values. These results showed that the biosorption of MB on the LPF follows well the PSO kinetics. Some authors have reported that adsorption of MB on different adsorbents fits well into the PSO kinetic model (Danish et al. 2018; Ho 2006). The rate constants $k_{2}$, were found as $0.0024,0.0045$ and $0.0116 \mathrm{~g} \mathrm{mg}^{-1} \mathrm{~min}^{-1}$ at 298, 308 and $318 \mathrm{~K}$, respectively (Table 2). It can be said that the biosorption rate is very fast and the equilibrium time is short (Fig. 7b). Sivalingam et al. (2019) reported that the rate of adsorption of MB on different adsorbents followed PSO kinetics and rate constant values were determined as $0.0035,0.0010$ and $0.0089 \mathrm{~g} \mathrm{mg}^{-1} \mathrm{~min}^{-1}$ for coal fly ash (CFA), nanozeolite (nFAZX) and commercial zeolite (CZX), respectively. Danish et al. (2018) were reported that the adsorption of $\mathrm{MB}$ on activated carbon derived from banana trunk (BTAC) followed PSO model kinetic and the rate constant $k_{2}$ was found as $0.056 \mathrm{~min}^{-1}$. Moghazy et al. (2019) investigated that micro-grinded dried biomass of two macro-algal species as complementary biosorbent materials for MB removal from wastewater. In the study, the kinetic data were well described by the PSO better than PFO kinetic model. Lebron et al. (2018) reported that the biosorption of MB best fitted to the PSO kinetic model for C. pyrenoidosa and $S$. maxima.

EM kinetic model This model is useful to energetically heterogeneous adsorbent surfaces (Siddiqui et al. 2018). Linear form of Elovich kinetic model was given as follows;

$q_{\mathrm{t}}=(1 / \beta) \ln (t)+(1 / \beta) \ln (\alpha \beta)$

where $\beta$ is a coefficient which represents rate of biosorption. $\alpha$ is the initial rate coefficient for the biosorption. The plot between $q_{\mathrm{t}}$ and $\ln (t)$ (Fig. 7c) gave $\alpha$ and $\beta$ values (Siddiqui et al. 2018). The values of $\alpha$ and $\beta$ were determined as $2.4437 \mathrm{mg} \mathrm{g}^{-1} \mathrm{~min}^{-1}$ and $0.1645 \mathrm{~g} \mathrm{mg}^{-1}$, respectively, at $298 \mathrm{~K}$. In addition, the values of $\alpha$ and $\beta$ increased with increasing temperature from 298 to $318 \mathrm{~K}$ (Table 2). The 

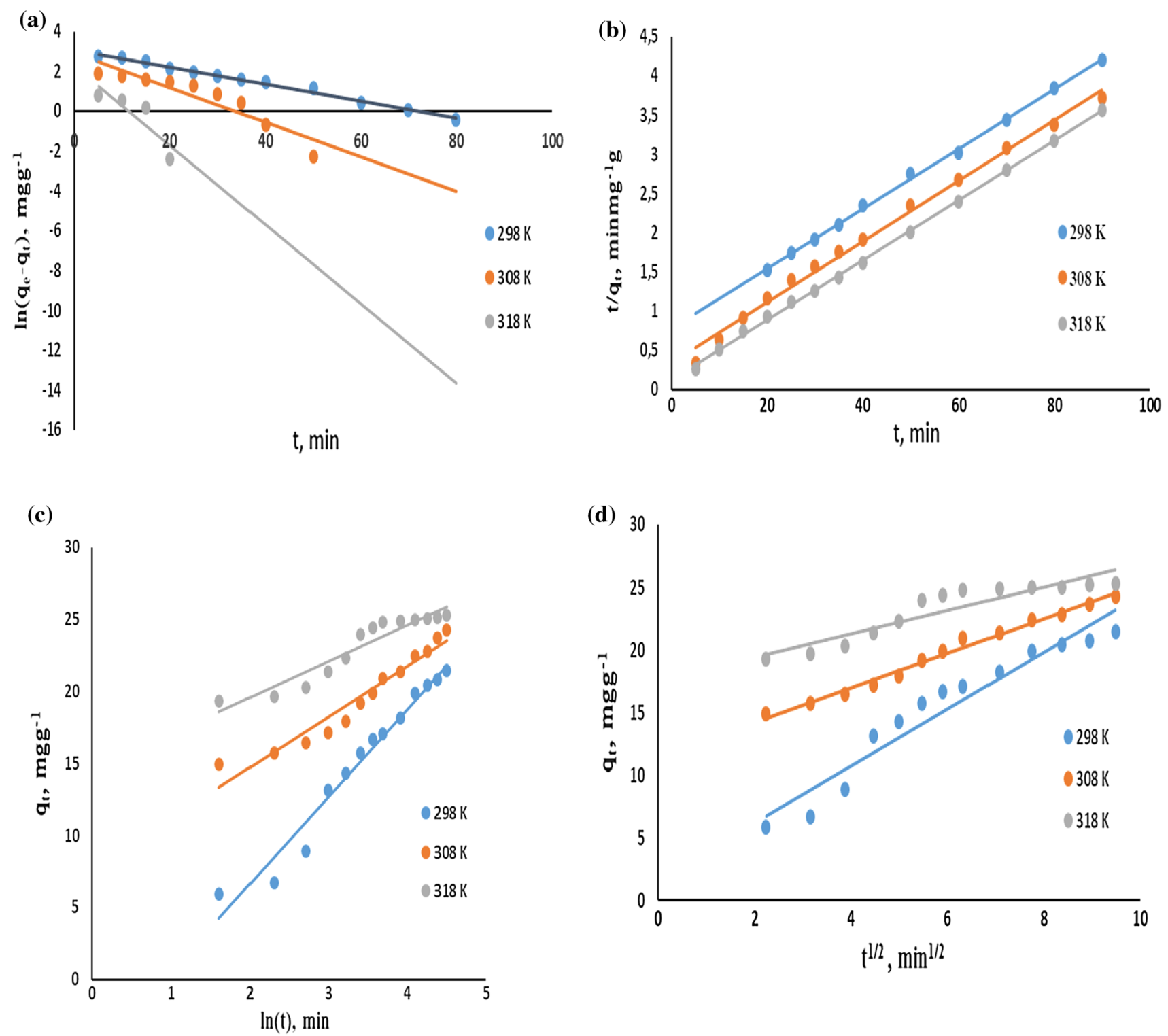

Fig. 7 The temperature effect on the biosorption kinetics (a PFO kinetics, b PSO kinetics, $\mathbf{c}$ EM kinetics, $\mathbf{d}$ IDM kinetics; 70 mg L ${ }^{-1}$ initial MB concentration)

$R^{2}$ values for EM kinetics were lower than that of the PSO model (Table 2). However, the results obtained from the other error functions (SSE, RMSE, $\chi^{2}$, AIC, AICc) show that this model can be used to describe the biosorption of MB on the LPF (Table 3). So, it can be said that the surface of the LPF was energetically heterogeneous.

IDM kinetic model This model has been widely applied for the evaluation of adsorption kinetics. According to this model, the bonding mechanisms of MB molecules on the LPF surface and intra-particle control the total rate of biosorption. The transfer mechanisms of MB molecules to the active sites of the LPF can be explained using intra-particle diffusion model (Cheung et al. 2007). Linear form of intra-particle diffusion model was given as follows;

$q_{\mathrm{t}}=k_{\mathrm{d}} t^{1 / 2}+\theta$

where $k_{\mathrm{d}}$ is the rate constant of intra-particle diffusion $\left(\mathrm{mg} \mathrm{g}^{-1} \mathrm{~min}^{-1 / 2}\right.$ ) and $\theta$ is the intercept.

The transfer of MB molecules was occurred some steps such as external diffusion from aqueous phase to the surface of the LPF, internal diffusion of the LPF surface, pore diffusion of intra-particle and biosorption on the pore surface. Moreover, 
Table 2 Model parameters calculated for various kinetic models at different temperatures (initial concentration: $70 \mathrm{mg} \mathrm{L}^{-1}$ )

\begin{tabular}{llccc}
\hline Model & Parameters & $298 \mathrm{~K}$ & $308 \mathrm{~K}$ & $318 \mathrm{~K}$ \\
\hline PFO & $k_{1}\left(\mathrm{~min}^{-1}\right)$ & 0.0429 & 0.0870 & 0.1983 \\
& $q_{\mathrm{e}}\left(\mathrm{mg} \mathrm{g}^{-1}\right)$ & 17.57 & 16.42 & 18.32 \\
& $R^{2}$ & 0.9891 & 0.8593 & 0.7552 \\
PSO & $k_{2}\left(\mathrm{~g} \mathrm{mg}^{-1} \mathrm{~min}^{-1}\right)$ & 0.0024 & 0.0045 & 0.0116 \\
& $k_{0}\left(\mathrm{~g} \mathrm{mg}^{-1} \mathrm{~min}^{-1}\right)$ & 1.2397 & 3.0046 & 7.9911 \\
& $q_{\mathrm{e}}\left(\mathrm{mg} \mathrm{g}^{-1}\right)$ & 20.09 & 23.59 & 25.32 \\
& $R^{2}$ & 0.9986 & 0.9936 & 0.9990 \\
EM & $\alpha\left(\mathrm{mg} \mathrm{g}^{-1} \mathrm{~min}^{-1}\right)$ & 2.4437 & 30.569 & 765.09 \\
& $\beta\left(\mathrm{g} \mathrm{mg}^{-1}\right)$ & 0.1645 & 0.2832 & 0.3942 \\
& $R^{2}$ & 0.9655 & 0.9418 & 0.9018 \\
IDM & $k_{\mathrm{d}}\left(\mathrm{mg} \mathrm{g}^{-1} \mathrm{~min}^{-1 / 2}\right)$ & 2.2695 & 1.3731 & 0.9341 \\
& $\theta\left(\mathrm{mg} \mathrm{g}^{-1}\right)$ & 1.6928 & 11.498 & 17.579 \\
& $R^{2}$ & 0.9324 & 0.9864 & 0.8471 \\
\hline
\end{tabular}

intra-particle diffusion was slow process. The plot between $q_{\mathrm{t}}$ and $t^{1 / 2}$ (Fig. 7d) gave the model constants. The $R^{2}$ values for IDM kinetics were lower than the PSO model (Table 2). However, the results obtained from the other error functions (SSE, RMSE, $\chi^{2}$, AIC, AICc) show that this model can be used to explain the biosorption of MB on the LPF (Table 3). From this, it can be said that it is not right to determine the model only with $R^{2}$ values. The rate constants of IDM $\left(k_{\mathrm{d}}\right)$ were found as $2.2695,1.3731$ and $0.9341 \mathrm{mg} \mathrm{g}^{-1} \mathrm{~min}^{-1 / 2}$ at 298,308 and $318 \mathrm{~K}$, respectively (Table 2).

\section{Kinetic model validity evaluation}

The validity of each model was determined by RMSE, SSE, $\left(\chi^{2}\right)$ and AIC, AICc tests. These error functions were expressed as follows;

$\operatorname{SSE}=\sum\left(q_{\mathrm{e}, \exp }-q_{\mathrm{e}, \mathrm{cal}}\right)^{2}$

$\operatorname{RMSE}=\left[\left(\sum\left(q_{\mathrm{e}, \mathrm{exp}}-q_{\mathrm{e}, \mathrm{cal}}\right)^{2}\right) / \mathrm{N}\right]^{1 / 2}$

where $N$ is the number of data. $q_{\mathrm{e}(\exp )}\left(\mathrm{mg} \mathrm{g}^{-1}\right)$ is the experimental value of $\mathrm{MB}$ biosorbed, $q_{\mathrm{e} \text { (cal) }}$ is the calculated value of MB biosorbed using a kinetic model $\left(\mathrm{mg} \mathrm{g}^{-1}\right)$. $\chi^{2}=\sum\left[\left(\left(q_{\mathrm{e}, \exp }-q_{\mathrm{e}, \mathrm{cal}}\right)^{2}\right) / q_{\mathrm{e}, \mathrm{cal}}\right]$

The fitting of experimental data to the kinetic models was determined by AIC (Wagenmakers and Farrell 2004; El-Naas et al. 2017).

$\mathrm{AIC}=2 p+N \ln (\mathrm{SSE} / N)$

where $p$ is the number of model parameters. If $N / P<40$, the second-order Akaike information criterion $\left(\mathrm{AIC}_{c}\right)$ should be calculated (Yao and Chen 2019; Bouabidia et al. 2018). It can be expressed as;

$\mathrm{AIC}_{c}=\mathrm{AIC}+[(2 p(p+1)) /(N-p-1)]$

The smaller the SSE, RMSE, $\chi^{2}$, AIC and $\mathrm{AIC}_{\mathrm{c}}$ values, the better the kinetic model (Table 3). It was calculated that the PSO, EM and IDM kinetic models yielded the lowest SSE, RMSE, $\chi^{2}$, AIC and $\mathrm{AIC}_{\mathrm{c}}$ values. According to the calculated error functions, higher correlation coefficients $\left(R^{2}\right)$ and closeness between calculated qe values from the kinetic model and experimental $q_{\mathrm{e}}$ values, it can be said that the PSO, EM and IDM kinetic models can be used for describing the biosorption kinetics of MB onto the LPF (Tables 2, $3)$.

\section{Activation energy}

The activation energy of the biosorption for MB onto the LPF was calculated using the linear form of Arrhenius equation;

$\ln k=\ln A-E_{\mathrm{a}} / R T$

where $k$ is the rate constant from PSO kinetic model $\left(\mathrm{g} \mathrm{mg}^{-1} \mathrm{~min}^{-1}\right), A$, temperature independent the Arrhenius constant $\left(\mathrm{g} \mathrm{mg}^{-1} \mathrm{~min}^{-1}\right), E_{\mathrm{a}}$, activation energy $\left(\mathrm{kJ} \mathrm{mol}^{-1}\right)$.

From the Arrhenius plots (Fig. 8), activation energy $\left(E_{\mathrm{a}}\right)$ of MB biosorption was calculated as $61.91 \mathrm{~kJ} \mathrm{~mol}^{-1}$. Activation energy values in the range of $5-40 \mathrm{~kJ} \mathrm{~mol}^{-1}$ represent physical sorption, and activation values in the range of $40-800 \mathrm{~kJ} \mathrm{~mol}^{-1}$ represent chemical sorption (Boparai et al. 2011). Therefore, it can be said that MB biosorption is chemical biosorption. Nithya et al. (2019) reported that
Table 3 Model validity evaluation among the various kinetic models used in this study $(298 \mathrm{~K})$

\begin{tabular}{llllllrr}
\hline Model & $q_{\mathrm{e}, \text { exp }}\left(\mathrm{mg} \mathrm{g}^{-1}\right)$ & $q_{\mathrm{e}, \mathrm{cal}}\left(\mathrm{mg} \mathrm{g}^{-1}\right)$ & SSE & RMSE & $\chi^{2}$ & AIC & AIC $_{\mathrm{c}}$ \\
\hline PFO & 21.44 & 17.57 & 56.32 & 2.08 & 3.40 & 53.84 & 55.04 \\
PSO & 21.44 & 20.09 & 35.62 & 1.65 & 2.51 & 47.88 & 49.08 \\
EM & 21.44 & 21.81 & 11.64 & 0.95 & 1.49 & 2.56 & 3.76 \\
IDM & 21.44 & 23.23 & 22.84 & 1.33 & 1.81 & 42.11 & 43.31 \\
\hline
\end{tabular}


Fig. 8 The Arrhenius plot for the biosorption

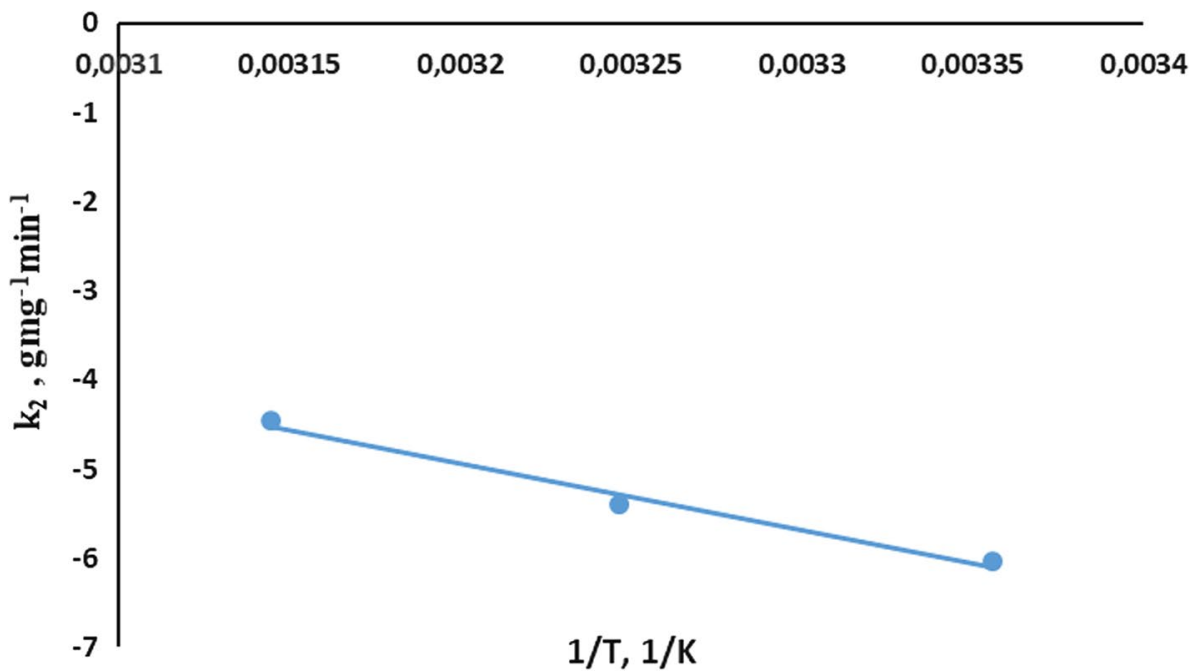

Table 4 Isotherm model parameters and correlation coefficients for the biosorption of MB onto the LPF

\begin{tabular}{llcc}
\hline & $298 \mathrm{~K}$ & $308 \mathrm{~K}$ & $318 \mathrm{~K}$ \\
\hline Freundlich & & & \\
$k_{f}$ & 0.5297 & 0.5124 & 0.1876 \\
$n$ & 1.3112 & 1.2269 & 1.4117 \\
$R 2$ & 0.9758 & 0.9508 & 0.9612 \\
$\mathrm{D}-\mathrm{R}$ & & & \\
$q_{\mathrm{m}}\left(\mathrm{mol} \mathrm{g}^{-1}\right)$ & 0.0258 & 0.0154 & 0.0293 \\
$K^{\prime}\left(\mathrm{mol}^{2} \mathrm{~kJ}^{-2}\right)$ & $11 \mathrm{E}-5$ & $9.1 \mathrm{E}-5$ & $8.9 \mathrm{E}-5$ \\
$E\left(\mathrm{~kJ} \mathrm{~mol}^{-1}\right)$ & 67.419 & 74.125 & 74.953 \\
$R 2$ & 0.9538 & 0.9483 & 0.9794 \\
\hline
\end{tabular}

the value of $\mathrm{E}_{\mathrm{a}}$ for removal of methylene blue by different adsorbent was $75.09 \mathrm{~kJ} \mathrm{~mol}^{-1}$.

\section{Biosorption isotherm studies}

The equilibrium time of MB onto the LPF was determined as $90 \mathrm{~min}$. To identify the biosorption mechanism of MB onto the LPF, isotherm studies were carried out. The experimental data were applied to the linearized form of Langmuir, Freundlich and D-R isotherm models, and the model parameters and correlation coefficients $\left(R^{2}\right)$ are given in Table 4 .

The Langmuir isotherm model assumes uniformly distributed homogenous surface, and uniformly distributed biosorption energy between the LPF surface and MB molecules for monolayer adsorption at a constant temperature. The linearized Langmuir isotherm was expressed as follows;

$1 / q_{\mathrm{e}}=1 /\left(q_{\mathrm{m}} K C_{\mathrm{e}}\right)+1 / q_{\mathrm{m}}$ where $K$ Langmuir constant $\left(\mathrm{L} \mathrm{mg}^{-1}\right), q_{\mathrm{m}}$ is the maximum concentration retained by the biosorbent $\left(\mathrm{mg} \mathrm{g}^{-1}\right), q_{\mathrm{e}}$ the biosorption capacity in equilibrium $\left(\mathrm{mg} \mathrm{g}^{-1}\right)$ and $C_{\mathrm{e}}$ is the $\mathrm{MB}$ concentration at equilibrium $\left(\mathrm{mg} \mathrm{L}^{-1}\right)$. The Langmuir constants were determined from the $1 / q_{\mathrm{e}}$ versus $1 / C_{\mathrm{e}}$ plots (Fig. 9a), but the negative values were found for $q_{\mathrm{m}}$ and $K$ (not given Table 4). This indicated that the Langmuir model was not suitable for the biosorption of MB onto the LPF. Hence, it can be said that the LPF has got non-uniformly distributed homogenous surface and non-uniformly distributed biosorption energy between the LPF surface and MB molecules. This result was confirmed by the biosorption kinetics that comply with the EM kinetic model. Also, SEM images supported this results as well (Fig. 4a-d).

The Freundlich isotherm model is based on the surface heterogeneity and the exponential distribution of active sites and their energies. The linearized Freundlich isotherm was expressed as follows:

$\ln q_{\mathrm{e}}=\ln k_{f}+n \ln C_{\mathrm{e}}$

where $k_{f}$ and $n$ represent the biosorption capacity and biosorption intensity, respectively. $n$ also indicates the relative energy distribution and the surface heterogeneity. The Freundlich isotherm constants and correlation coefficients were determined from the plots of $\ln q_{\mathrm{e}} \mathrm{vs} \ln C_{\mathrm{e}}$ (Fig. 9b) at each temperature, and given Table 4. $n$ values were found greater than 1, indicating favourable biosorption and formation of relatively strong bond between the MB molecules and the LPF. Similar results have been reported in the literature (Rashid et al. 2019; Wong et al. 2016; Djilani et al. 2015). Lebron et al. (2018) reported that the biosorption of MB onto C. pyrenoidosa and S. maxima. best described by Freundlich and Temkin isotherm models.

The $\mathrm{D}-\mathrm{R}$ isotherm model is temperature independent model, and it predicts the biosorption energy per unit of 

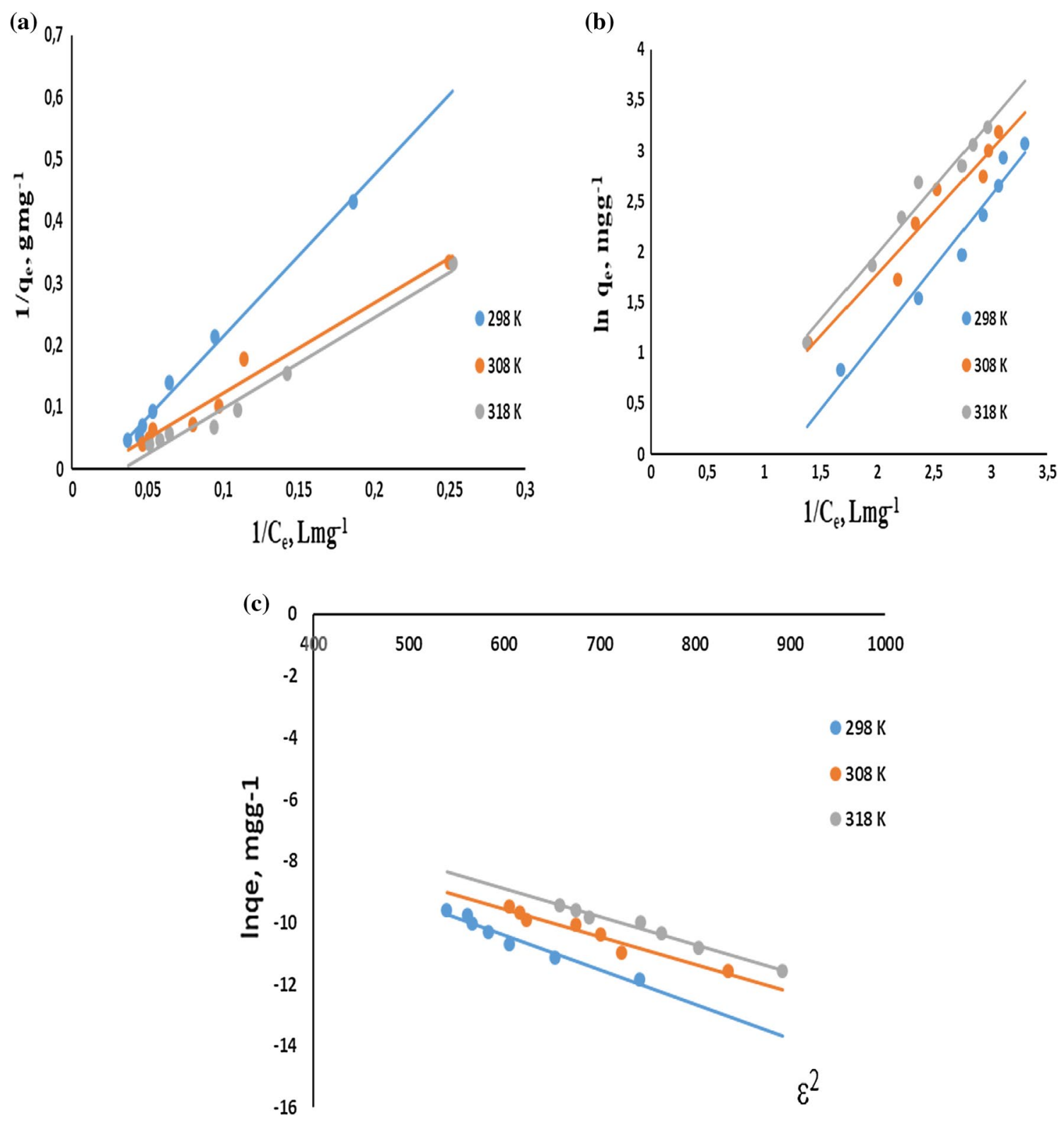

Fig. 9 The Langmuir isotherms $\mathbf{a}$, the Freundlich isotherms $\mathbf{b}$ and the D-R isotherms $\mathbf{c}$ for the biosorption of MB onto the LPF at various temperatures

the biosorbent and a maximum biosorption capacity for the LPF. The linear form of the D-R isotherm was expressed as follows;

$\ln q_{\mathrm{e}}=\ln q_{\mathrm{m}}-K^{\prime} \varepsilon^{2}$

$\varepsilon($ Polanyi potential $)=R T \ln \left(1+1 / C_{\mathrm{e}}\right)$

where $K^{\prime}$ the bisorption energy constant $\left(\mathrm{mol}^{2} \mathrm{~kJ}^{-2}\right), C_{\mathrm{e}}$ the equilibrium concentration of $\mathrm{MB}\left(\mathrm{mol} \mathrm{L}^{-1}\right), q_{\mathrm{e}}$ is the biosorbed MB amount per unit the LPF $\left(\mathrm{mol} \mathrm{g}^{-1}\right), q_{\mathrm{m}}$ the theoretical monolayer saturation capacity $\left(\mathrm{mol} \mathrm{g}^{-1}\right) . E$ mean adsorption energy $\left(\mathrm{kJ} \mathrm{mol}^{-1}\right)$ was shown as follows:

$E=1 /\left(2 K^{\prime}\right)^{1 / 2}$

The plots of $\ln q_{\mathrm{e}}$ versus $\varepsilon^{2}$ are shown in Fig. 9c, and the D-R constants obtained from the plots are given in Table 4. $q_{\mathrm{m}}$ the theoretical monolayer saturation capacities $\left(\mathrm{mol} \mathrm{g}^{-1}\right)$ were found as $0.0154 \mathrm{~mol} \mathrm{~g}^{-1}$ at $308 \mathrm{~K}$. The value of $E$ constant gives information about the biosorption process is chemical or physical. If $1<E<8 \mathrm{~kJ} \mathrm{~mol}^{-1}$, the process 
Table 5 Isotherm model validity evaluation (308 K)

\begin{tabular}{llllll}
\hline Model & $\begin{array}{l}q_{\mathrm{e}, \text { exp }} \\
\left(\mathrm{mg} \mathrm{g}^{-1}\right)\end{array}$ & $\begin{array}{l}q_{\mathrm{e}, \mathrm{cal}} \\
\left(\mathrm{mg} \mathrm{g}^{-1}\right)\end{array}$ & $\begin{array}{l}\text { Deviation } \\
(\%)\end{array}$ & SSE & $\chi^{2}$ \\
\hline Freundlich & 24.25 & 22.11 & 8.82 & 4.587 & 0.2074 \\
D-R & 24.25 & 26.80 & 10.52 & 9.052 & 29.138 \\
\hline
\end{tabular}

is physical biosorption; if $8<E<16 \mathrm{~kJ} \mathrm{~mol}^{-1}$, it is ion exchange biosorption; and if $E>16 \mathrm{~kJ} \mathrm{~mol}^{-1}$, it is chemical biosorption (Chen et al. 2019). As shown Table 4, $E$ values were calculated to be in the range of $67.42-74.95 \mathrm{~kJ} \mathrm{~mol}^{-1}$, which was higher than $16 \mathrm{~kJ} \mathrm{~mol}^{-1}$. Therefore, the type of biosorption of MB on the LPF was chemical biosorption. It was also confirmed by activation energy. It can be said that the biosorption of MB on the LPF involved electrostatic interaction, hydrogen bond, $\pi-\pi$ interactions and surface participation.

\section{Isotherm model validity evaluation}

Model validity evaluation was carried out among the studied isotherm models in terms of error functions, closeness (deviation \%) between calculated $q_{\mathrm{e}}$ values from the isotherm model and experimental $q_{\mathrm{e}}$ values and higher correlation coefficients $\left(R^{2}\right)$ (Tables 4,5$)$.

The values of SSE and $\chi^{2}$ obtained for the Freundlich isotherm were lower than that of the D-R isotherm model under all conditions studied. Also, the deviations \% between $q_{\mathrm{e}, \mathrm{cal}}$ and $q_{\mathrm{e}, \mathrm{exp}}$ were lower for the Freundlich isotherm than that of D-R isotherm model. The good conformity to the Freundlich isotherm indicated the surface heterogeneity. Therefore, the surface of the LPF was decided energetically heterogeneous due to the good fit of the biosorption kinetics to the EM model. Also, good compliance with the D-R and Freundlich isotherms supported this result. Moreover, SEM images of the LPF revealed that the LPF has heterogeneous surface (Fig. 4a).

\section{Conclusions}

In this study, biosorption kinetic and equilibrium studies for removal of MB dye from aqueous solution by the LPF, as a novel biosorbent, were investigated. The type of biosorption of MB onto the LPF was defined as chemical biosorption process. The surface of the LPF was decided energetically heterogeneous due to the good fit of the biosorption kinetics to the EM kinetic model and good compliance with the Freundlich and D-R isotherm models.

High biosorption efficiency achieved in a short equilibrium time. The biosorption rate is very fast. Thus, the nonliving LPF biomass is a promising biosorbent for the removal of MB dye from aqueous media. The LPF is a natural, renewable, sustainable, economic and eco-friendly biosorbent. Because the LPF which is a common lichen species can be easily collected from the conifer-hardwood forests and can be used without any chemical treatment. The results found in this study will contribute as an alternative method for the removal of MB from wastewater.

Acknowledgements Authors would like to thank to Prof.Dr.Atilla Yildız (Ankara University) for his kind help in the lichen providing.

\section{Compliance with ethical standards}

Conflict of interest The authors declare no conflicts of interests.

Open Access This article is licensed under a Creative Commons Attribution 4.0 International License, which permits use, sharing, adaptation, distribution and reproduction in any medium or format, as long as you give appropriate credit to the original author(s) and the source, provide a link to the Creative Commons licence, and indicate if changes were made. The images or other third party material in this article are included in the article's Creative Commons licence, unless indicated otherwise in a credit line to the material. If material is not included in the article's Creative Commons licence and your intended use is not permitted by statutory regulation or exceeds the permitted use, you will need to obtain permission directly from the copyright holder. To view a copy of this licence, visit http://creativecommons.org/licenses/by/4.0/.

\section{References}

Adegoke KA, Bello OS (2015) Dye sequestration using agricultural wastes as adsorbents. Water Res Ind 12:8-24

Altenor S, Carene B, Emmanuel E, Lambert J, Ehrhardt JJ, Gaspard S (2009) Adsorption studies of methylene blue and phenol onto vetiver roots activated carbon prepared by chemical activation. $\mathbf{J}$ Hazard Mater 165:1029-1039

Aslan A, Güllüce M, Sökmen M, Adıgüzel A, Sahin F, Özkan H (2006) Antioxidant and antimicrobial properties of the lichens cladonia foliacea., dermatocarpon miniatum., everinia divaricata., Evernia prunastri., and neofuscella pulla. Pharm Biol 44(4):247-252

Bazrafshan E, Alipour MR, Mahvi AH (2015) Textile wastewater treatment by application of combined chemical coagulation, electrocoagulation, and adsorption processes. Desalin Water Treat 1-13

Boparai KH, Joseph M, O'carroll MD (2011) Kinetics and thermodynamics of cadmium ion removal by adsorption onto nanozerovalent iron particles. J Hazard Mater 186(1):458-465

Bouabidia ZB, El-Naasa MH, Cortesa D, McKayb G (2018) SteelMaking dust as a potential adsorbent for the removal of lead (II) from an aqueous solution. Chem Eng J 334:837-844

Chen S, Qin C, Wang T, Chen F, Li X, Hou H, Zhou M (2019) Study on the adsorption of dyestuffs with different properties by sludge-rice husk biochar: adsorption capacity, isotherm, kinetic, thermodynamics and mechanism. J Mol Liq 285:62-74

Cheung WH, Szeto YS, McKay G (2007) Intraparticle diffusion processes during acid dye adsorption onto chitosan. Bioresour Technol 98:2897-2904

Danish M, Ahmad T, Nadhari WNAW, Ahmad M, Khanday WA, Ziyang L, Pin Z (2018) Optimization of banana trunk-activated 
carbon production for methylene blue-contaminated water treatment. Appl Water Sci 8:9

Djilani C, Zaghdoudi R, Djazi F, Bouchekima B, Lallam A, Modarressi A, RogalskI M (2015) Adsorption of dyes on activated carbon prepared from apricot stones and commercial activated carbon. J Taiwan Inst Chem Eng 53:112-121

El-Naas MH, Alhaija MA, Al-Zuhair S (2017) Evaluation of an activated carbon packed bed for the adsorption of phenols from petroleum refinery wastewater. Environ Sci Pollut Res 24:7511-7520

Ferrero F (2007) Dye removal by low cost adsorbents: Hazelnut shells in comparison with wood sawdust. J Hazard Mater 142:144-152

Goyal N, Bulasara VK, Barman S (2018) Removal of emerging contaminants daidzein and coumestrol from water by nanozeolite beta modified with tetrasubstituted ammonium cation. J Hazard Mater 344:417-430

Gül ÜD, Şenol ZM, Gürsoy N, Şimşek S (2019) Effective UO22+ removal from aqueous solutions using lichen biomass as a natural and low-cost biosorbent. J Environ Radioactiv 205:93-100

Gupta VK, Pathania D, Agarwal S, Singh P (2012) Adsorptional photocatalytic degradation of methylene blue onto pectin-CuS nanocomposite under solar light. J Hazard Mater 243:179-186

Hale ME (1974) The Biology of Lichens, 2nd edn. Edward Arnold, London

Hamdaoui Q (2006) Batch study of liquid-phase adsorption of methylene blue using cedar sawdust and crushed brick. J Hazard Mater $135: 264-273$

Ho YS (2006) Second-order kinetic model for the sorption of cadmium onto tree fern: A comparison of linear and non-linear methods. Water Res 40:119-125

Hua S, Yu X, Li F, Duan J, Ji H, Liu W (2017) Hydrogen titanate nanosheets with both adsorptive and photocatalytic properties used for organic dyes removal. Colloids Surf A Physicochem Eng Asp 516:211-218

Khalili MS, Zare K, Moradi O, Sillanpää M (2018) Preparation and characterization of MWCNT-COOH-cellulose-MgO NP nanocomposite as adsorbent for removal of methylene blue from aqueous solutions: isotherm, thermodynamic and kinetic studies. J Nanostruct Chem 8:103-121

Kilıc Z, Atakol O, Aras S, Cansaran-Duman D, Emregul E (2014) Biosorption properties of zinc(II) from aqueous solutions by Pseudevernia furfuracea (L.) Zopf. J Air Waste Manag Assoc 64:1112-1121

Komaty S, Letertre M, Dang HD, Jungnickel H, Laux P, Luch A, Carrié D, Merdrignac-Conanec O, Bazureau J-P, Gauffre F, Tomasi S, Paquin L (2016) Sample preparation for an optimized extraction of localized metabolites inlichens: application to Pseudevernia furfuracea. Talanta 150:525-530

Koyuncu H (2008) Adsorption kinetics of 3-hydroxybenzaldehyde on native and activated. Bentonite Appl Clay Sci 38:279-287

Koyuncu H, Kul AR (2019) Removal of aniline from aqueous solution by activated kaolinite: kinetic, equilibrium and thermodynamic studies. Colloids Surf A Physicochem Eng Asp 569:59-66

Koyuncu H, Kul AR, Yıldız N, Çalımlı A, Ceylan H (2007) Equilibrium and kinetic studies for the sorption of 3-methoxybenzaldehyde on activated kaolinites. J Hazard Mater 141:128-139

Kul AR, Koyuncu H (2010) Adsorption of $\mathrm{Pb}(\mathrm{II})$ ions from aqueous solution by native and activated bentonite: kinetic, equilibrium and thermodynamic study. J Hazard Mater 179:332-339

Lagergren S (1898) Above the theory of so-called adsorption of soluble substances. Kungliga Svenska Vetensk Handl 24:1-39

Lebron YAR, Moreira VR, Santos LVS, Jacob RS (2018) Remediation of methylene blue from aqueous solution by Chlorella pyrenoidosa and Spirulina maxima biosorption: equilibrium, kinetics, thermodynamics and optimization studies. J Environ Chem Eng 6:6680-6690
Ledakowicz S, Zylla R, Pazdzior K, Wrebiak J, Sojka-Ledakowicz J (2017) Integration of ozonation and biological treatment of industrial wastewater from dyehouse. Ozone Sci Eng 39:357-365

Ma L, Wang G, Jiang C, Bao H, Xu Q (2018) Synthesis of core-shell TiO2@g-C3N4 hollow microspheres for efficient photocatalytic degradation of rhodamine B under visible light. Appl Surf Sci 430:263-272

Malaspinaa P, Modenesib P, Giordania P (2018) Physiological response of two varieties of the lichen Pseudevernia furfuracea to atmospheric pollution. Ecol Indic 86:27-34

Moghazy Reda M, Labena A, Husien Sh (2019) Eco-friendly complementary biosorption process of methylene blue using micro-sized dried biosorbents of two macro-algal species (Ulva fasciata and Sargassum dentifolium): full factorial design, equilibrium, and kinetic studies. Int J Biol Macromol 134:330-343

Nezamzadeh-Ejhieh A, Karimi-Shamsabadi M (2014) Comparison of photocatalytic efficiency of supported $\mathrm{CuO}$ onto micro and nano particles of zeolite $\mathrm{X}$ in photodecolorization of Methylene blue and Methyl orange aqueous mixture. Appl Catal Gen 477:83-92

Nithya R, Sivasankari C, Thirunavukkarasu A, Selvasembian R (2019) Fast removal of methylene blue and $\mathrm{Hg}$ (II) from aqueous solution using a novel super-adsorbent containing residues of glycine and maleic acid. J Hazard Mater 369:642-654

Paoli L, Pisani T, Guttová A, Sardella G, Loppi S (2011) Physiological and chemical response of lichens transplanted in and around an industrial area of south Italy: relationship with the lichen diversity. Ecotoxicol Environ Safe 74:650-657

Paolia L, Munzi S, Guttová A, Senko D, Sardella G, Loppi S (2015) Lichens as suitable indicators of the biological effects of atmospheric pollutants around a municipal solid waste incinerator (SItaly). Ecol Indic 52:362-370

Rashid J, Tehreem F, Rehman A, Kumar R (2019) Synthesis using natural functionalization of activated carbon from pumpkin peels for decolourization of aqueous methylene blue. Sci Total Environ 671:369-376

Salimi A, Roosta A (2019) Experimental solubility and thermodynamic aspects of methylene blue in different solvents. Thermochim Acta 675:134-139

Sarikurkcu C, Kocak MS, Calapoglu M, Ocal C, Tepe B (2016) Biological and phytochemical evaluation: Pseudevernia furfuracea as an alternative multifunctional agent. J Funct Food 24:11-17

Siddiqui SI, Rathi G, Chaudhry SA (2018) Acid washed black cumin seed powder preparation for adsorption of methylene blue dye from aqueous solution: thermodynamic, kinetic and isotherm studies. J Mol Liq 264:275-284

Sivalingam S, Kella T, Maharana M, Sen S (2019) Efficient sono-sorptive elimination of methylene blue by fly ashderived nano-zeolite $\mathrm{X}$ : process optimization, isotherm and kinetic studies. J Clean Prod 208:1241-1254

Subramaniam R, Ponnusamy SK (2015) Novel adsorbent from agricultural waste (cashew NUT shell) for methylene blue dye removal: optimization by response surface Methodology. Water Res Ind 11:64-70

Van derWat L, Forbes PBC (2015) Lichens as biomonitors for organic air pollutants. Trend Anal Chem 64:165-172

Wagenmakers E-J, Farrell S (2004) AIC model selection using Akaike weights. Psychonomic Bullet Rev 11(1):192-196

Wang W, Zhao Y, Bai H, Zhang T, Ibarra-Galvan V, Song S (2018) Methylene blue removal from water using the hydrogel beads of poly(vinyl alcohol)-sodium alginate- chitosan-montmorillonite. Carbohydr Polym 198:518-528

Wong KT, Eu NC, Ibrahim S, Kim H, Yoon Y, Jang M (2016) Recyclable magnetite loaded palm shell-waste based activated carbon for the effective removal of methylene blue from aqueous solution. $\mathbf{J}$ Clean Prod 115:337-342 
Yao C, Chen T (2019) An improved regression method for kinetics of adsorption from aqueous solutions. J Water Process Eng 31:100840

Zeng L, Xie M, Zhang Q, Kang Y, Guo X, Xiao H, Peng Y, Luo J (2015) Chitosan/organic rectorite composite for the magnetic uptake of methylene blue and methyl orange. Carbohydr Polym 123:89-98

Zhang Y-R, Wang S-Q, Shen S-L, Zhao B-X (2013) A novel water treatment magnetic nanomaterial for removal of anionic and cationic dyes under severe condition. Chem Eng J 233:258-264
Publisher's Note Springer Nature remains neutral with regard to jurisdictional claims in published maps and institutional affiliations. 